\title{
Dossî́
}

\section{Humanizar a educação, globalizar a esperança}

\author{
SONIA DE ITOZ ${ }^{1}$ \\ SÉrgio Rogério Azevedo JunqueirA ${ }^{2}$
}

Resumo: $\mathrm{O}$ artigo se propõe a fazer uma leitura compreensiva de alguns aspectos contundentes do documento "Educar ao Humanismo Solidário", dirigido às escolas e universidades católicas. O texto, publicado em 22 de setembro de 2017 pela Congregação para a Educação Católica, discorre sobre as diretrizes propostas para a educação católica atual. As orientações "humanizar a educação", "cultura do diálogo" e "semear esperança" se fazem diretrizes para o processo de humanizar a educação na escola católica hoje. O documento assume deliberadamente que é a pessoa que deve ser colocada no centro do processo de educar. Para isso, deve ser posicionada em um quadro de relações que compõem uma comunidade viva, interdependente, vinculada a um destino comum e habitante da mesma aldeia que é este Universo. É importante ressaltar que o documento coloca-se em plena conformidade a textos, orientações e ensinamentos dos últimos pontificados na Igreja Católica. Por essa razão, o artigo em pauta assume, no percurso de toda a matéria, as sábias falas e posicionamentos do Papa Francisco, já que estas sustentam a percepção do "Educar ao Humanismo Solidário".

Palavras-chave: Educação. Escola confessional. Pastoral escolar.

\section{Humanize education, globalize hope}

\begin{abstract}
The article proposes a comprehensive reading of some strong aspects of the document "Educating for Solidarity Humanism", directed to Catholic schools and universities. The text, published on September 22, 2017, by the Congregation for Catholic Education, discusses the guidelines proposed for current Catholic education. The guidelines, "humanize education"; "Culture of dialogue"; and "sow hope", are guidelines for the process of humanizing education in the Catholic school today. The document deliberately assumes that it is the person who should be placed at the center of the process of educating, for this must be placed in a framework of relations that make up a living, interdependent community, linked to a common destiny, and inhabitant of the same village that is this Universe. It is important to emphasize that the document is in full conformity with the texts, guidelines and teachings of the last pontificates in the Catholic Church. For this reason, the article in question assumes, in the course of all matter, the wise speeches and positions of Pope Francis, since they support the perception of "Educating for Solidarity Humanism".

Keywords: Education. Confessional school. Pastoral school.
\end{abstract}




\section{Humanizar la educación, globalizar la esperanza}

Resumen: El artículo se propone a una lectura comprensiva de algunos aspectos fundamentales del documento "Educar para el Humanismo Solidario", dirigido a las escuelas y universidades católicas. El texto, publicado el 22 de septiembre de 2017, por la Congregación para la Educación Católica, discurre sobre las directrices propuestas para la educación católica actual. Las orientaciones "humanizar la educación”; "Cultura del diálogo"; y "sembrar esperanza", se tornan directrices para el proceso de humanizar la educación en la escuela católica en la actualidad. El documento asume claramente que la persona debe ser colocada en el centro del proceso de educar, para ello debe colocarse en un marco de relaciones que componen una comunidad viva, interdependiente, vinculada a un destino común, y habitante de la misma aldea que es este Universo. Es importante resaltar que el documento se sitúa en plena consonancia con los textos, orientaciones y enseñanzas de los últimos pontificados de la Iglesia Católica. Por esta razón, el artículo en pauta asume, a lo largo de toda la materia, las sabias palabras y posicionamientos del Papa Francisco, ya que ellas sostienen la percepción de "Educar para el Humanismo Solidario".

Palabras clave: Educación. Escuela confesional. Pastoral escolar.

\section{Introdução}

Este artigo está vinculado a uma série de projetos referentes à pastoral escolar, visando compreender e articular os pressupostos da educação escolar realizada nos espaços confessionais no cenário brasileiro. Foram organizados pelo Grupo de Pesquisa Educação e Religião (GPER) ${ }^{3}$ desde 2001 para subsidiar a construção de fundamentos para a pastoral escolar, especialmente a partir dos documentos eclesiais. Este artigo, como parte desse processo, é um exercício de compreensão da atualização de elementos significativos e pertinentes às orientações do magistério da Igreja, para aprimorar as orientações da evangelização nas escolas católicas. Assim, o documento "Educar ao Humanismo Solidário" articula indicativos de que há demandas no cenário atual que orientam a ação educacional nas instituições católicas e que apontam maneiras possíveis e melhores de educar as novas gerações (CONGREGAÇÃO PARA A EDUCAÇÃO CATÓLICA, 2017). Assumindo uma perspectiva de "humanizar a educação", exercitar uma "cultura do diálogo" e "semear a esperança”, a orientação convoca a escola e a universidade católica a encarregarem-se, intencionalmente, de ajudar os alunos a perceber que "a globalização das relações é também a globalização da solidariedade" (CONGREGAÇÃO PARA A EDUCAÇÃO CATÓLICA, 2017, n. 5), o que faz com que a dinâmica dos projetos, conteúdos, metodologias e estratégias leve a associar princípios éticos com escolhas de vida e a valorizar redes de cooperação primeiro entre si e, por consequência, com a realidade atual de mundo. Em outras palavras, o texto da Congregação para a Educação Católica coloca um modelo de educação humanista solidária desde sua concepção, 
porém enfatiza a ação e execução dela, a fim de que se cuide da humanidade das pessoas. É uma proposta que orienta as instituições católicas para que se instaure o ato solidário na concepção e no cotidiano do processo educativo.

\title{
Cenário e contexto
}

Na celebração dos 50 anos da Carta Encíclica Populorum Progressio, do Papa Paulo VI, de 1967, a qual evoca o desenvolvimento dos povos, a Congregação para a Educação Católica publicou um novo documento dirigido às escolas e universidades católicas. A orientação "Educar ao Humanismo Solidário" faz parte das publicações da Fundação Pontifícia Gravissimum Educationis, constituída pelo Papa Francisco para contribuir e promover o compromisso da Igreja no campo da educação, por intermédio das escolas e universidades católicas.

\begin{abstract}
Os conteúdos deste humanismo solidário precisam ser vividos e testemunhados, formulados e transmitidos num mundo assinalado por múltiplas diferenças culturais, atravessado por visões heterogéneas do bem e da vida, e caracterizado pela convivência de diferentes crenças. Para tornar possível este processo - como afirma o Papa Francisco na encíclica Laudato Si' - "é preciso ter presente que os modelos de pensamento influem realmente nos comportamentos. A educação será ineficaz e os seus esforços estéreis, se não se preocupar também por difundir um novo modelo relativo ao ser humano, à vida, à sociedade e à relação com a natureza". Com o presente documento a Congregação para a Educação Católica visa propor as diretrizes principais da educação para o humanismo solidário (CONGREGAÇÃO PARA A EDUCAÇÃO CATÓLICA, 2017, n. 5).
\end{abstract}

Para o Papa Francisco, nesse momento histórico, as escolas e universidades católicas são chamadas a contraporem-se a um modelo de globalização sem visão e sem esperança, o qual produz, por consequência, mais violência, discriminação, conflitos, segregações, enfim, sofrimentos e misérias para as populações em geral. O documento "Educar ao Humanismo Solidário" propõe algumas diretrizes amplas, mas que instigam a educação católica a assumir e a desenvolver, na própria ação de educar, a humanização da educação. Em outras palavras, fazer da educação, na instituição escolar católica, um processo em que cada pessoa possa desenvolver atitudes profundas de dignidade e reverência à vida, realizando a própria vocação e, assim, participar ativamente e contribuir para uma vocação maior dada à comunidade humana.

A questão social, como disse o Papa Bento XVI, é hoje uma questão antropológica que requer uma função educativa que não se pode mais adiar. Por isso, é necessário um "um novo ímpeto do 
pensamento para compreender melhor as implicações do fato de sermos uma família; a interação entre os povos da terra chama-nos a esse ímpeto, para que a integração se verifique sob o signo da solidariedade, e não da marginalização" (CONGREGAÇÃO PARA A EDUCAÇÃO CATÓLICA, 2017, n. 6).

Durante a Conferência de Imprensa, em 22 de setembro de 2017, na apresentação da orientação "Educar ao Humanismo Solidário", o cardeal Giuseppe Versaldi, prefeito da Congregação para a Educação Católica, disse que é necessário e urgente "colocar a pessoa no centro da educação, num quadro de relações que compõem uma comunidade viva, interdependente, vinculada a um destino comum".

Nessa linha, colocando-se mediante os desafios atuais das sociedades e as demandas dos espaços educacionais, a Congregação para a Educação Católica abre um convite público e convoca as instituições educacionais católicas a comprometerem-se com uma educação que atenda às gerações atuais, às famílias e à comunidade escolar, para que, assim, possam desenvolver, instaurar e promover uma cultura do diálogo.

\footnotetext{
"Conhecedora da humanidade", como descrita pela Populorum progressio cinquenta anos atrás, a Igreja tem seja a missão como a experiência para indicar os percursos educativos adequados aos desafios atuais. A sua visão educativa está ao serviço da realização dos maiores objetivos da humanidade. Tais objetivos foram destacados, previamente, na Declaração Gravissimum educationis: o desenvolvimento harmónico das qualidades físicas, morais e intelectuais finalizados ao gradual amadurecimento do sentido de responsabilidade; a conquista da verdadeira liberdade; a positiva e prudente educação sexual. Ao longo desta perspectiva, intuía-se que a educação devia estar ao serviço de um novo humanismo, no qual a pessoa social estivesse aberta ao diálogo e cooperasse na promoção do bem comum (CONGREGAÇÃ̃O PARA A EDUCAÇÃO CATÓLICA, 2017, n. 7).
}

Com afinco, é colocado o mesmo desafio pelo Papa Francisco às instituições educacionais católicas. Diz ele que "mediante a educação para o humanismo solidário cuida-se da humanidade do futuro, a posteridade, para a qual é preciso ser solidário fazendo hoje escolhas responsáveis” (PAPA FRANCISCO, 2017a).

\section{Humanizar a educação}

Desde o seu nascimento, a universidade e a escola católica têm razão de existir porque dão sua contribuição histórica na formação da pessoa e do cidadão, assim como na própria organização social da vida humana. No entanto, e 
por consequência da própria identidade cristã, as instituições educacionais católicas sabem que, para constituir o sujeito ativo e o indivíduo comprometido, é necessário apresentar e levar cada um a inserir-se em uma comunidade. É a comunidade que garante e dá respaldo à necessidade humana intrínseca de fazer-se ao colocar-se mediante o outro.

\begin{abstract}
"Humanizar a educação" significa colocar a pessoa no centro da educação, num quadro de relações que compõem uma comunidade viva, interdependente, vinculada a um destino comum. É desta maneira que é caracterizado o humanismo solidário (CONGREGAÇÃO PARA A EDUCAÇÃO CATÓLICA, 2017, n. 8).
\end{abstract}

Por essa razão, hoje, mais do que nunca, é preciso que a educação católica se posicione "frente ao individualismo invasivo que rende humanamente pobres e culturalmente improdutivos, é necessário humanizar a educação" (PAPA FRANCISCO apud JUANA; PICHEL, 2017).

Essa é uma das fortes razões pela qual o documento "Educar ao Humanismo Solidário" faz um apelo à universidade e à escola católica. Estas são desafiadas a dar um passo mais profundo, ou seja, a se preocuparem e a fazer uma educação para além dos aspectos da formação humana e acadêmica. A elas é pedido que ofereçam horizontes abertos à transcendência e que coloquem a educação a serviço de um humanismo que seja integral-integrante-integrador. Para isso:

É necessário, portanto, humanizar a educação, ou seja, torná-la um processo em que cada pessoa possa desenvolver as próprias atitudes profundas, a própria vocação e assim contribuir para a vocação da própria comunidade (EDUCAR AO HUMANISMO SOLIDÁRIO, 2017, n. 8).

A Igreja tem por missão primeira humanizar, o que, para o Papa Francisco, é preciso fazer:

[...] como uma mãe educadora, [que] olha sempre para as novas gerações na perspectiva da formação da pessoa humana tanto do ponto de vista de seu fim último como do bem das sociedades das quais o homem é membro (PAPA FRANCISCO, 2017b).

No documento "Educar ao Humanismo Solidário", ter um olhar para humanizar a educação é propor-se a despertar o desejo de aprender e a instaurar uma sede constante de investigar as curiosidades dos saberes. O objetivo último é provocar e levar às novas gerações a ressignificar o sentido do próprio existir no contexto das sociedades, do tempo e da história. 


\section{Cultura do diálogo}

Tratar de uma cultura do diálogo não é simples e menos ainda fácil na atual conjuntura de mundo. Em linhas gerais, a cultura do diálogo passa por uma prática contundente de respeito profundo e de uma apelativa consideração na relação com o outro, ou seja, faz sempre abrir portas, nunca encerrar as possíveis fronteiras. É também uma postura perante a vida que leva a detectar e a perceber o que há de bom no outro, em vez de simplesmente censurar o modo de ser diferente. É um diálogo que consegue fazer com que um se aproxime do outro de forma sempre renovada e instigadora.

A cultura do diálogo não significa simplesmente conversar para se conhecer, de modo a facilitar o encontro entre cidadãos de diferentes culturas. Mas o autêntico diálogo ocorre num quadro ético de requisitos e atitudes formativas, bem como de objetivos sociais. Os requisitos éticos para dialogar são a liberdade e a igualdade: os participantes do diálogo devem estar livres de seus interesses contingentes e estar dispostos a reconhecer a dignidade de todos os interlocutores. Esses comportamentos são baseados na coerência com o próprio universo de valores. Isso se traduz na intenção geral de conciliar as ações com as declarações, isto é, de associar os princípios éticos anunciados (por exemplo paz, igualdade, respeito, democracia...) com as escolhas sociais e civis realizadas. Trata-se de uma "gramática do diálogo", como indicado pelo Papa Francisco, capaz de "construir pontes e [...] encontrar respostas para os desafios do nosso tempo" (CONGREGAÇÃO PARA A EDUCAÇÃO CATÓLICA, 2017, n. 12).

Diz o Papa Francisco que o:

Nosso mundo se converteu em uma aldeia global com múltiplos processos de interação, onde cada pessoa pertence à humanidade $\mathrm{e}$ compartilha a esperança de um futuro melhor com a família inteira dos povos (PAPA FRANCISCO apud JUANA; PICHEL, 2017).

Sabe-se, no entanto, que essa aldeia global ainda não considera todos na mesma dignidade de filhos de um mesmo Pai, o nosso Deus. Muitos ainda sofrem discriminação nas suas múltiplas condições de seres humanos, de raças, credos, orientações e tantas outras. Com isso carregam pesados fardos e se tornam vítimas de violência, abandono, pobreza, exploração, discriminação, migração, guerras, o que limita as liberdades fundamentais e leva à cultura do descarte.

Assim, "[...] as instituições católicas de educação são chamadas, em primeira linha, a praticar a gramática do diálogo que forma o encontro e a valorização das diversidades culturais e religiosas" (PAPA FRANCISCO apud JUANA; PICHEL, 2017). 
Desenvolver uma cultura do diálogo leva a desencadear no processo educativo uma escuta atenta, uma vontade de aprender com o outro e uma abertura de acolhida ao diferente.

Trata-se, em primeiro lugar, de um processo educativo no qual a busca por uma convivência pacífica e enriquecedora enraíza-se no mais amplo conceito de ser humano - na sua caracterização psicológica, cultural e espiritual - para além de qualquer forma de egocentrismo e etnocentrismo, segundo uma concepção de desenvolvimento integral e transcendente da pessoa e da sociedade (CONGREGAÇÃO PARA A EDUCAÇÃO CATÓLICA, 2017, n. 15).

A cultura do diálogo caracteriza um auscultar reverente, em um diálogo profundo e verdadeiro com o outro, na sua plena dignidade, e torna-se fonte de encontro, de entendimento do coração e de percepção de intenções e dos desejos humanos mais profundos.

[...] a dimensão intercultural é frequentemente vivida nas salas de aula de todos os tipos e níveis, bem como nas instituições universitárias, portanto é a partir delas que se deve difundir a cultura do diálogo. $\mathrm{O}$ quadro de valores, no qual vive, pensa e age o cidadão formado para o diálogo, é baseado em princípios relacionais (gratuidade, liberdade, igualdade, coerência, paz e bem comum) que entram de modo positivo e decisivo nos programas didáticos e formativos das instituições que prezam o humanismo solidário (CONGREGAÇÃO PARA A EDUCAÇÃO CATÓLICA, 2017, n. 14).

\section{Semear a esperança}

Para o Papa Francisco, "o homem não pode viver sem esperança”. A educação é sempre entendida como espaço gerador de esperanças. Educar é um dar à luz, é um fazer crescer, que se situa na dinâmica do compartilhar informações, dados, sistematizações, conhecimentos, sabedorias, ou seja, "semear esperança" é abrir-se à própria vida. A vida, sabe-se, é a fonte fecunda de onde brota a esperança, a indagação, o extasiamento, a bondade, a verdade, em última instância, uma comunhão com todo o Universo.

Globalizar a esperança é a missão específica da educação para o humanismo solidário. Uma missão que se realiza por meio da construção de relações educativas e pedagógicas que formem para o amor cristão, que criem grupos assentes na solidariedade, nas quais o bem comum esteja associado virtuosamente ao bem de cada um dos seus membros, que transformem o conteúdo das ciências em conformidade com a plena realização da pessoa e da sua pertença à 
humanidade. É justamente a educação cristã que pode desenvolver tal tarefa primária, pois a educação "é fazer nascer, é fazer crescer, coloca-se na dinâmica do dar a vida. E a vida que nasce é a fonte mais borbulhante de esperança" (CONGREGAÇÃO PARA A EDUCAÇÃO CATÓLICA, 2017, n. 18).

Nesse aspecto, a condição juvenil é latente da vida que se projeta e se faz em direção ao futuro.

É necessário, portanto, humanizar a educação, ou seja, torná-la um processo em que cada pessoa possa desenvolver as próprias atitudes profundas, a própria vocação e assim contribuir para a vocação da própria comunidade (PAPA FRANCISCO, 2017a).

Assim, semear a esperança exige colocar-se no lugar do outro, não apenas como troca, mas em uma:

[...] cooperação, em seu sentido mais prodigioso: o de supor afetos, permitir as escolhas, os desejos, o desenvolvimento moral como construção dos próprios sujeitos, um trabalho constante com estruturas lógicas e as relações de confiança (TOGNETTA, 2002, p. 33).

A esperança é o que leva a inserir-se na vida, a lutar pela vida e a não se conformar com as mesmices do cotidiano. Na esperança é que está a lucidez que se faz atenta às situações para transformar a realidade e a vida. Mediante o sentido mais profundo, solidário e comprometido do ser humano sempre aflora, com uma ternura que é própria de cada ser humano, a esperança.

Globalizar a esperança significa também promover as esperanças da globalização. Por um lado, a globalização multiplicou as oportunidades de crescimento e abriu as relações sociais para novas e inéditas possibilidades. Por outro, além de alguns benefícios, esta causou desigualdades, explorações, além de levar, de modo perverso, alguns povos a sofrer uma exclusão dramática dos âmbitos do bem-estar. Uma globalização sem visão, sem esperança, sem uma mensagem que seja, ao mesmo tempo, anúncio e vida concreta, está destinada a produzir conflitos e a gerar sofrimentos e misérias (CONGREGAÇÃO PARA A EDUCAÇÃO CATÓLICA, 2017, n. 19).

No entanto, nas novas gerações, para que a esperança persista e se torne eficaz, precisa ser semeada, tratada, cuidada e carinhosamente educada. Esperança torna-se, assim, a atitude concreta e realista de cada ação educativa, que mostra um mundo diferente, onde os jovens possam vivenciar a certeza de que tudo pode ser melhor daquilo que se vive hoje. 
Provocar a esperança, no processo educativo das novas gerações, é vivenciar propostas que dão sentido para o hoje e remetem à busca de um amanhã melhor para todos. A esperança se faz, portanto, na forma de construir respostas significativas às situações do cotidiano. Especificamente o que suscita a esperança aparece mediante as dificuldades e as alegrias da vida. Quer sejam os ganhos, quer sejam as perdas enfrentadas, elas enchem o coração de ternura e coragem para oferecer uma resposta diante dos desafios do dia a dia.

\section{Missão da Igreja: educação que humaniza, dialoga, edifica a espe- rança e evangeliza}

O horizonte da evangelização, entendido como educação que humaniza, dialoga e edifica a esperança, hoje está diante de um individualismo invasivo, o que torna as pessoas pobres de humanidade e culturalmente limitadas. Essa é uma das principais razões pelas quais coloca-se o apelo - e também um imenso desafio - para humanizar a educação das instituições educacionais católicas.

Uma educação humanizada, portanto, não se limita a fornecer um serviço de formação, mas cuida dos seus resultados no quadro geral das capacidades pessoais, morais e sociais dos participantes no processo educativo; não pede simplesmente ao professor para ensinar e ao aluno para aprender, mas exorta cada um a viver, estudar e agir de acordo com as premissas do humanismo solidário; não prevê espaços de divisão e contraposição mas, pelo contrário, oferece lugares de encontro e debate para realizar projetos educativos válidos; trata-se de uma educação - ao mesmo tempo - sólida e aberta, que derruba os muros da exclusividade, promovendo a riqueza e a diversidade dos talentos individuais e expandindo o perímetro da própria sala de aula a cada âmbito da experiência social em que a educação pode gerar solidariedade, partilha, comunhão (CONGREGAÇÃ̃ PARA A EDUCAÇÃO CATÓLICA, 2017, n. 10).

É também no horizonte da evangelização que se semeiam, plantam-se e colhem-se esperanças para oferecer uma contribuição válida à missão de ser Igreja inserida nas realidades e culturas. Para isso, "O Papa Francisco criou a fundação 'Gravissimum educationis' com as 'finalidades científicas e culturais para promover a educação católica no mundo" (CONGREGAÇÃO PARA A EDUCAÇÃO CATÓLICA, 2017, n. 30), o que se torna uma ocasião "para traçar as orientações dos futuros compromissos" sobre princípios fundamentais da educação cristã nas escolas. Todos os educadores das instituições católicas precisam estar conscientes e assumir um projeto que leve a "ajudar os jovens a serem construtores de um mundo mais solidário e pacífico" (PAPA FRANCISCO apud PORTAL CATÓLICO, 2017). 
Faz parte do educar, das instituições católicas, o fomento para a cultura do diálogo como exercício cidadão, especialmente em tempos em que o mundo se transformou em uma aldeia global. Ou seja, "cada pessoa pertence à humanidade e compartilha a esperança de um futuro melhor com a família inteira dos povos" (PAPA FRANCISCO apud JUANA; PICHEL, 2017).

As instituições católicas de educação estão sendo convocadas mais uma vez a praticar um tipo de conteúdo educacional que desenvolva o diálogo. É preciso, no entanto, que seja um diálogo que instaure o encontro e a valorização das diversidades culturais e religiosas. Que seja um autêntico diálogo capaz de "construir pontes e de encontrar respostas para os desafios do nosso tempo" (PAPA FRANCISCO, 2017a).

Para cumprir a sua função, os projetos de formação da educação para o humanismo solidário visam alguns objetivos fundamentais. Primeiramente, o objetivo principal é permitir que cada cidadão se sinta ativamente participante na construção do humanismo solidário. Os instrumentos utilizados devem promover o pluralismo, estabelecendo espaços de diálogo destinados à representação das questões éticas e normativas. A educação para o humanismo solidário deve assegurar, com uma atenção especial, que a aprendizagem das ciências corresponda à consciência de um universo ético no qual a pessoa age. Em particular, esta correta concepção do universo ético deve orientar para a abertura de horizontes do bem comum progressivamente mais amplos, até englobar toda a família humana (CONGREGAÇÃO PARA A EDUCAÇÃO CATÓLICA, 2017, n. 20).

É um modelo de diálogo que faz desabrochar, abrir-se, ouvir e ir ao encontro. Um aprendizado que se coloca na perspectiva da abertura, do acolhimento e da contribuição para com o outro, para que as novas gerações, educadas ao diálogo por esse modo cristão, sejam pessoas da escuta e da participação e, assim, possam construir pontes e encontrar novas respostas aos muitos desafios do hoje. A última diretriz, indicada no documento "Educar ao Humanismo Solidário", é a de uma educação que saiba semear a esperança.

Tenho certeza que os jovens de hoje têm muita necessidade dessa vida que constrói futuro. Por isso, o verdadeiro educador é como um pai e uma mãe que transmite uma vida capaz de futuro. Para ter essa atitude é preciso escutar os jovens: o trabalho da escuta, o propor-se a escutar os jovens! (PAPA FRANCISCO apud PORTAL CATÓLICO, 2017).

Semear a esperança é um modelo de educação humanizada que não se limita a fornecer um serviço de formação. É uma educação que cuida das ca- 
pacidades pessoais, morais e sociais dos participantes do processo educativo. $\mathrm{O}$ professor ensina e o aluno aprende, mas de acordo com as premissas de um humanismo solidário, participativo, comprometido e que busca ser coerente com princípios e valores cristãos. Para isso, promove espaços e lugares de encontro, de debate, contempla e acolhe a diversidade que faz gerar solidariedade, partilha e comunhão.

\section{Panorâmica geral do documento "Educar ao Humanismo Solidário"}

A publicação do documento "Educar ao Humanismo Solidário" foi acompanhada e referendada pela Fundação Pontifícia Gravissimum Educationis, constituída pelo Papa Francisco para desenvolver e promover o compromisso efetivo da Igreja no campo da educação.

Com o objetivo de dar uma alma ao mundo global, atravessado por mudanças constantes, a Congregação para a Educação Católica relança a prioridade da construção da "civilização do amor" e exorta todos aqueles que, por profissão e por vocação, estão comprometidos nos processos educativos - em todos os níveis -, a viver com dedicação e sabedoria essa sua experiência, em nome dos princípios e valores abordados. O nosso Dicastério - depois do Congresso Mundial "Educar hoje e amanhã. Uma paixão que se renova" (Roma-Castel Gandolfo, 18-21 de novembro de 2015) - reiterou as reflexões e os desafios encontrados tanto pelos professores, alunos e pais quanto pelas Igrejas particulares, Famílias religiosas e Associações comprometidas no vasto universo da educação (CONGREGAÇÃO PARA A EDUCAÇÃO CATÓLICA, 2017, n. 29).

O texto do documento convoca as escolas e universidades católicas a se contraporem a uma globalização sem visão da realidade do mundo e sem a esperança que nutre a vida. "Globalizar a esperança significa também promover as esperanças da globalização. Por um lado, a globalização multiplicou as oportunidades de crescimento e abriu as relações sociais para novas e inéditas possibilidades" (CONGREGAÇÃO PARA A EDUCAÇÃO CATÓLICA, 2017, n. 5).

A Congregação para a Educação Católica evoca, no texto do documento, os ensinamentos dos últimos pontificados, dizendo que é necessário colocar a pessoa no centro da educação. No entanto, isso se faz mediante um quadro de relações que compõe uma comunidade real, interdependente e que está vinculada a um destino comum na aldeia global.

[...] a Igreja tem [...] a missão como a experiência para indicar os percursos educativos adequados aos desafios atuais. A sua visão educativa está ao serviço da realização dos maiores objetivos da humanidade. Tais objetivos foram destacados, previamente, na 
Declaração Gravissimum educationis: o desenvolvimento harmônico das qualidades físicas, morais e intelectuais finalizados ao gradual amadurecimento do sentido de responsabilidade; a conquista da verdadeira liberdade; a positiva e prudente educação sexual (CONGREGAÇÃO PARA A EDUCAÇÃO CATÓLICA, 2017, n. 7).

O documento também aponta para um cenário de crises, que vai muito além das questões econômicas, culturais e das migrações. É uma crise que passa pela política, pelas culturas, pelas crenças, pelo meio ambiente. Enfim, tem-se o retrato de um humanismo decadente nos seus valores fundamentais. Vive-se um humanismo fundamentado nos paradigmas da concorrência de mercados, de instabilidade econômica, de indiferença, do tecnocrático, entre outros, o que instaurou a falta total de uma ética de relações com a humanidade toda e com o planeta.

O mundo contemporâneo, multifacetado e em constante mudança, é atravessado por múltiplas crises. Estas são de várias naturezas: crises econômicas, financeiras, de trabalho; crises políticas, democráticas, de participação; crises ambientais e naturais; crises demográficas e migratórias, etc. Os fenómenos provocados por tais crises revelam diariamente o seu carácter dramático. A paz é constantemente ameaçada e, juntamente com as guerras travadas entre exércitos, difunde-se a insegurança causada pelo terrorismo internacional, cujos ataques provocam sentimentos de desconfiança recíproca e ódio, assim como favorece o desenvolvimento de sentimentos populistas, demagógicos, que correm o risco de agravar os problemas, favorecendo a radicalização do conflito entre culturas diferentes. Guerras, conflitos e terrorismo são algumas vezes a causa, outras vezes o efeito das desigualdades econômicas e da injusta distribuição dos bens da criação (CONGREGAÇÃO PARA A EDUCAÇÃO CATÓLICA, 2017, n. 3).

"Estamos diante de um processo que foi oportunamente definido como uma mudança de época. Isso revela um humanismo decadente, fundado geralmente no paradigma da indiferença" (CONGREGAÇÃO PARA A EDUCAÇÃO CATÓLICA, 2017, n. 4). Por essa razão, o documento "Educar ao Humanismo Solidário" convoca a uma educação mais atenta às relações entre gerações, para que seja de respeito à família e de promoção de uma cultura do diálogo. A proposta feita às instituições católicas é que estas ajudem os alunos a associar seus princípios éticos às suas escolhas de vida, para que, assim, possam se comprometer a promover redes de cooperação e solidariedade com todas as dimensões da vida.

Uma educação para o humanismo solidário desenvolve redes de cooperação nos diferentes âmbitos do exercício da atividade educativa e, em particular, da formação académica. Primeiramente, exige dos agentes da educação a adoção de um comportamento 
propenso à colaboração. Particularmente, prefere a colegialidade do corpo docente na preparação dos programas de formação e de cooperação, bem como a colaboração entre os alunos, no que diz respeito às modalidades de aprendizagem e aos ambientes de formação. Mais ainda, enquanto células vivas do humanismo solidário, ligadas por um pacto educacional e por uma ética inter-geracional, a solidariedade entre quem ensina e quem aprende deve ser progressivamente inclusiva, plural e democrática (CONGREGAÇÃO PARA A EDUCAÇÃO CATÓLICA, 2017, n. 25).

O texto também faz referência e realça o papel das religiões, desafiando que elas, mediante suas propostas de valores éticos, defendam uma globalização da esperança como condição da plenitude humana. "Mediante a educação para o humanismo solidário cuida-se da humanidade do futuro, a posteridade, para a qual é preciso ser solidário fazendo hoje escolhas responsáveis" (PAPA FRANCISCO, 2017a).

No pluralismo ético-religioso, em vez de serem um obstáculo, as religiões podem portanto estar ao serviço da convivência pública. A partir dos valores positivos de amor, esperança e salvação, num quadro de relações performativo e coerente, as religiões podem contribuir de modo significativo para a realização dos objetivos sociais de paz e justiça. Em tal perspectiva, a cultura do diálogo defende uma concepção prepositiva das relações civis. Em vez de reduzir a religiosidade à esfera individual, privada e confidencial, e obrigar os cidadãos a seguir no espaço público apenas as normas éticas e jurídicas do Estado, a cultura do diálogo inverte os termos da relação e exorta as crenças religiosas a professar em público os próprios valores éticos positivos (CONGREGAÇÃO PARA A EDUCAÇÃO CATÓLICA, 2017, n. 13).

E, por último, conclui o documento com um apelo a todos os que estão envolvidos com a educação nas instituições católicas para que vivam com dedicação e sabedoria essa experiência. E que, em nome dos princípios e valores para humanizar a educação, busquem desenvolver uma cultura do diálogo para que se deem conta de semear a esperança.

\section{O espaço da evangelização}

Os elementos abordados nesse documento, que orientam a educação como um todo, mostram que quanto mais a evangelização for mediada pela pastoral escolar, mais será fiel ao seu propósito. Para a pastoral operacionalizar a missão que lhe cabe, verifica-se que é preciso pensar as ações a serem estabelecidas para que estejam em consonância com os propósitos, fundamentos e princípios da educação e ao propósito evangelizador. 
É necessário, então, por meio da esperança da salvação, ser já sinal vivo dessa esperança. No mundo globalizado como é possível propagar a mensagem de salvação de Jesus Cristo? "Não é a ciência que redime o homem. O homem é redimido pelo amor". A caridade cristã propõe gramáticas sociais universalizantes e inclusivas. Tal caridade informa as ciências que, preenchidas por ela, acompanharão o homem em busca do sentido e da verdade na criação. A educação para o humanismo solidário deve então começar a partir da certeza da mensagem de esperança contida na verdade de Jesus Cristo. Cabe a ela, portanto, irradiar tal esperança, que é a mensagem transmitida pela razão e pela vida ativa, com os povos de todas as partes do mundo (CONGREGAÇÃO PARA A EDUCAÇÃO CATÓLICA, 2017, n. 17).

Assim como o aprender é um processo contínuo e gradativo, a evangelização também requer um andamento que contemple começo, meio e fim, que atenda a objetivos claros e coerentes com os da instituição e que contribua, de fato, para o crescimento humano e espiritual dos estudantes (PANINI, 1997, p. 5).

A escola católica tem a tarefa de veicular suas razões de ser, é um espaço de Igreja que evangeliza, e o diferencial, na maioria das escolas católicas, era atribuída aos profissionais do ensino religioso. Com a definição da especificidade dessa área do conhecimento, que passou a aprofundar o fenômeno religioso na sua diversidade e complexidade, emergiu a questão: quem na escola católica irá abordar, de forma sistemática, a sua identidade e missão?

Diante dessa questão surge o desafio de seguir definindo as especificidades do ensino religioso, especialmente sua integração no projeto político-pedagógico da escola. Em paralelo, surge também a urgência de melhor organizar e explicitar a ação evangelizadora, inerente à atividade da escola católica, avançando na consciência de que todo projeto educativo (ou proposta pedagógica, ou projeto pedagógico, conforme nomenclatura de cada escola) é que deverá garantir a identidade e a missão da escola católica. Assim, a maioria dessas instituições sentiu a necessidade de incluir em seu organograma a pastoral escolar (CONGREGAÇÃO PARA A EDUCAÇÃO CATÓLICA, 1977, p. 33-37).

A educação e a formação, escolar e universitária, sempre estiveram no centro da proposta da Igreja Católica na vida pública. A Igreja defendeu a liberdade de educação quando, em culturas secularizadas e laicistas, os espaços designados para a formação aos valores religiosos pareciam reduzir-se. Por meio da educação, Ela continuou a fornecer princípios e valores à convivência pública quando as sociedades modernas, iludidas pelas metas científicas e tecnológicas, jurídicas e culturais, acreditavam que a cultura católica fosse insignificante. Hoje, assim como em cada época, a Igreja Católica tem a responsabilidade de contribuir, com o seu patrimônio de verdades e valores, para a construção do humanismo solidário, 
por um mundo pronto a atualizar a profecia contida na Encíclica Populorum progressio (CONGREGAÇÃO PARA A EDUCAÇÃO CATÓLICA, 2017, n. 28).

As escolas católicas têm a missão de propor uma educação integral da pessoa por meio de um projeto educativo fundamentado nos princípios evangélicos, que contribua para dar o direcionamento, qualificação e sentido para a vida de toda comunidade educativa. É nessa perspectiva que o Documento de Aparecida (CELAM, 2007, n. 338) afirma:

\begin{abstract}
Propõe-se que nas instituições católicas a educação na fé seja integral e transversal em todo o currículo, levando em consideração o processo de formação para encontrar a Cristo e para viver como discípulos e missionários e inserindo nela verdadeiros processos de iniciação cristã. Ao mesmo tempo, recomenda-se que a comunidade educativa (diretores, mestres, pessoal administrativo, alunos, pais de família etc.), enquanto autêntica comunidade eclesial e centro de evangelização assuma seu papel de formadora de discípulos e missionários em todos os seus estratos. Que, a partir daí, em comunhão com a comunidade cristã que é sua matriz, promova um serviço pastoral no setor em que se insere especialmente dos jovens, da família, da catequese e da promoção humana dos mais pobres. Esses objetivos são essenciais nos processos de admissão de alunos, em suas famílias e na contratação dos docentes.
\end{abstract}

Nesse ambiente, a pastoral escolar tem a tarefa de manter viva a consciência da missão educativa evangelizadora de toda a escola, despertando para a responsabilidade individual de cada educador, ao mesmo tempo que aprofunda com toda a comunidade educativa os valores do Evangelho. Naturalmente, realiza atividades evangelizadoras com toda a comunidade educativa, na esfera da espiritualidade, formação e prática da caridade, mediante planejamento. Ora, para que a presença da pastoral escolar de fato cumpra o seu papel, requer agentes de pastoral com qualidades e formação adequada, sobretudo para refletir sobre sua presença e atuação (ANJOS; ITOZ; JUNQUEIRA, 2015).

\title{
Considerações finais
}

A educação está a serviço do "aprender", o qual se radica na liberdade, passa pela libertação da pessoa e culmina na abertura a uma ordem social humanizadora. É possível dizer que é por meio dessa abertura que o ser humano transcende a si mesmo e descobre o Ser Supremo que dá sentido à sua existência e, ao estabelecer com Ele uma relação vital, aprende a lhe ser fiel em todos os momentos da sua existência e de sua atividade. Portanto, diante dessa linha de 
reflexão, propõe-se que a escola - de forma específica, a escola católica - ofereça a seus estudantes a possibilidade da experiência de uma realidade superior a eles mesmos, de forma decisiva para sua realização mais plena e uma nova forma de relacionar-se com seus pares. Em outras palavras:

Uma educação humanizada, portanto, não se limita a fornecer um serviço de formação, mas cuida dos seus resultados no quadro geral das capacidades pessoais, morais e sociais dos participantes no processo educativo; não pede simplesmente ao professor para ensinar e ao aluno para aprender, mas exorta cada um a viver, estudar e agir de acordo com as premissas do humanismo solidário; não prevê espaços de divisão e contraposição mas, pelo contrário, oferece lugares de encontro e debate para realizar projetos educativos válidos; trata-se de uma educação - ao mesmo tempo - sólida e aberta, que derruba os muros da exclusividade, promovendo a riqueza e a diversidade dos talentos individuais e expandindo o perímetro da própria sala de aula a cada âmbito da experiência social em que a educação pode gerar solidariedade, partilha, comunhão (EDUCAR AO HUMANISMO SOLIDÁRIO, 2017, n. 10).

Por essa razão, quando se fala da educação na perspectiva cristã, refere-se explicitamente à opção por uma ética do respeito ao outro, do diálogo e da fraternidade, acentuando o caráter comunitário e, portanto, o relacionamento social como fator básico do processo educativo. Ao pensar a escola como um todo, no seu cotidiano, compete a todos os seguimentos encaminhar as crianças e os jovens para o respeito mútuo, despertando-lhes a atenção e a estima pelos direitos humanos, pela prática da justiça e pelo cumprimento do dever, sensibilizando-os para as exigências de uma fraternidade universal e concreta (CNBB, 1992).

A instituição de educação católica é convocada hoje pelo Papa Francisco a "dar a razão da sua esperança" (1 Pedro 3,15). Assim, somente uma educação proposta e vivida na perspectiva das novas realidades, que se coloca na dimensão da aldeia global, é que será fiel ao seu chamado primeiro. E toda a ação educativa tornar-se-á testemunha de uma educação que humaniza, dialoga e edifica a esperança.

Com o objetivo de dar uma alma ao mundo global, atravessado por mudanças constantes, a Congregação para a Educação Católica relança a prioridade da construção da "civilização do amor" e exorta todos aqueles que, por profissão e por vocação, estão comprometidos nos processos educativos - em todos os níveis -, a viver com dedicação e sabedoria essa sua experiência, em nome dos princípios e valores abordados (CONGREGAÇÃO PARA A EDUCAÇÃO CATÓLICA 2017, n. 29). 
Para tal, a Igreja, na América Latina, propõe aos educadores cristãos a organização de uma educação que:

$\checkmark$ Humanize e personalize o homem, para nele criar o lugar onde possa revelar-se e ser escutada a boa-nova.

$\checkmark$ Integre a dinâmica do cotidiano educativo no processo social latino-americano, impregnado por uma cultura radicalmente cristã, na qual coexistam valores e contravalores, luzes e sombras e que, por isso, necessita ser constantemente reevangelizada.

$\checkmark$ Exerça a função crítica, própria da verdadeira educação, procurando regenerar permanentemente, do ponto de vista da educação, os princípios culturais e as normas da integração social que possibilitem a criação de uma nova sociedade, mais fraterna, ou seja, uma educação para a justiça, em que o educando seja, de fato, o sujeito não só do seu desenvolvimento, mas também o despertando para o serviço do desenvolvimento da comunidade.

Enfim, para ser coerente com os princípios da fé, uma escola que se define como católica deve empenhar-se por oferecer uma educação evangélico-libertadora que inclua, com a capacitação técnica e acadêmica de qualidade, a formação para a solidariedade humana, o incentivo para o cumprimento dos próprios deveres e a promoção dos direitos de todos, desabrochando em verdadeira fraternidade e abertura à transcendência e aos valores do Reino de Deus.

Recebido em: 31/09/2017

Revisado pelo autor em: 23/10/2017 Aceito para publicação em: 31/10/2017

\section{Notas}

1 Mestrado em Educação pela Pontifícia Universidade Católica de São Paulo (PUC/SP) (1993). Graduação em Filosofia pelas Faculdades Associadas do Ipiranga (FAI) (1990) e graduação em Teologia pela Faculdade de Teologia Nossa Senhora da Assumpção (1990). Coordenadora do Departamento de Estudos Filosóficos, Sociológicos e Ensino Religioso e de Pastoral Escolar do Colégio Emilie de Villeneuve/São Paulo. E-mail: soniadeitoz@gmail.com

2 Livre-docente (2012). Pós-Doutorado em Ciência da Religião pela Pontifícia Universidade Católica de São Paulo (PUC/SP) (2010). Doutorado (2000) e Mestrado (1996) em Ciências da Educação pela Univeristà Pontificia Salesiana (Roma, Itália). Licenciatura em Pedagogia pela Universidade de Uberaba (1990). Bacharelado em Ciências Religiosas pelo Instituto Superior de Ciências Religiosas (1987). Líder do Grupo de Pesquisa Educação e Religião. Diretor/presidente do Instituto de Pesquisa e Formação Educação e Religião, Paraná, Brasil. E-mail: srjunq@gmail.com

3 GPER é um grupo de pesquisadores que articulam a construção do ensino religioso como uma área de conhecimento para ampliar e aprofundar os estudos acadêmicos para a identidade pedagógica do componente do currículo escolar. 


\section{Referências}

AGÊNCIA ECCLESIA. Vaticano: "Humanizar a educação" é o desafio global que o Papa lança à Igreja. Lisboa, 22 set. 2017. Disponível em: $<$ http://www.agencia.ecclesia.pt/noticias/vaticano/vaticano-humanizar-a-educacao-e-o-desafio-global-que-o-papa-lanca-a-igreja/> . Acesso em: 23 out. 2017. ANJOS, Márcio Fabri dos; ITOZ, Sonia; JUNQUEIRA, Sergio. Pastoral escolar: práticas e provocações. Aparecida: Santuário, 2015.

CELAM. Documento de Aparecida - Texto Conclusivo da V Conferência Geral do Episcopado Latino-Americano e do Caribe. São Paulo: Paulus-Paulina, 2007.

CNBB - CONFERÊNCIA NACIONAL DOS BISPOS DO BRASIL. Educação, Igreja e Sociedade. São Paulo: Paulinas, 1992. (Documento da CNBB, n. 47).

CONGREGAÇÃO PARA A EDUCAÇÃO CATÓLICA. A Escola Católica. Vaticano: Tipografia Poliglota Vaticano, 1977.

Educar ao humanismo solidário. Para construir uma "civilização do amor" 50 anos após a Populorum progressio. Roma, Solenidade da Ressurreição de Nosso Senhor Jesus Cristo Festa da Páscoa, 16 de abril de 2017. Disponível em: <http://www.vatican.va/roman_curia/congregations/ccatheduc/documents/rc_con_ccatheduc_doc_20170416_educare-umanesimo-solidale_po.html>. Acesso em: 23 out. 2017.

JUANA, Álvaro de; PICHEL, Miguel Pérez. 3 chaves essenciais para a educação explicadas pelo Papa Francisco. ACI Digital, 10 fev. 2017. Disponível em: $<$ http://www.acidigital.com/noticias/3-chaves-essenciais-para-a-educacao-explicadas-pelo-papa-francisco-49498/>. Acesso em: $1^{\circ}$ nov. 2017.

PANINI, Joaquim. Apresentação do Documento à Pastoral da Escola Católica. Cadernos da AEC do Brasil, Brasília, n. 67, p. 5-6, 1997.

PAPA FRANCISCO. Carta Encíclica Populorum Progressio. Sobre La Necesidad De Promover El Desarrollo De Los Pueblos. Roma, 26 mar. 1967. Disponível em: <http://w2.vatican.va/content/paul-vi/es/encyclicals/documents/hf_p-vi_enc_26031967_populorum.html>. Acesso em: 23 out. 2017.

Conferência de Imprensa. Cidade do Vaticano, 22 nov. 2017a.

Discurso aos participantes na Plenária da Congregação para a

Educação Católica. Sala Clementina, 9 fev. 2017b. Disponível em: < https:// w2.vatican.va/content/francesco/pt/speeches/2017/february/documents/ papa-francesco_20170209_plenaria-educazione-cattolica.html>. Acesso em: 23 out. 2017. 
PAULO VI. Declaração Gravissimum Educationis sobre a Educação Cristã. Roma, 28 out. 1965. Disponível em: <http://www.vatican.va/archive/hist_ councils/ii_vatican_council/documents/vat-ii_decl_19651028_gravissimum-educationis_po.html>. Acesso em: 23 out. 2017.

PORTAL CATÓLICO. Educação católica humanizada, com diálogo e esperança contribui à missão da Igreja. 10 fev. 2017. Disponível em: <http:/ /www. portalcatolico.org.br/single-post/2017/02/10/Educa $\% \mathrm{C} 3 \% \mathrm{~A} 7 \% \mathrm{C} 3 \% \mathrm{~A} 3 \mathrm{o}-\mathrm{ca}-$ $\mathrm{t} \% \mathrm{C} 3 \% \mathrm{~B} 3$ lica-humanizada-com-di $\% \mathrm{C} 3 \%$ A 1 logo-e-esperan $\% \mathrm{C} 3 \% \mathrm{~A} 7 \mathrm{a}$-contribui-\%C3\%A0-miss\%C3\%A3o-da-Igreja>. Acesso em: $1^{\circ}$ nov. 2017.

TOGNETTA, Luciene Regina. A construção da solidariedade e a educação do sentimento na escola. Campinas: Editora: Mercado de Letras/FAPESP, 2003. 